\title{
EFEITO DA HIDRÓLISE ENZIMÁTICA SOBRE PROPRIEDADES FUNCIONAIS DE CASEÍNA BOVINA COAGULAdA PELA AÇÃO DA QUIMOSINA
}

\author{
Janesca Alban ROMAN ${ }^{2}$, Valdemiro Carlos SGARBIERI
}

\section{RESUMO}

Este trabalho teve como objetivo verificar a influência do grau de hidrólise sobre as propriedades funcionais hidrofilicas (capacidade de absorção espontânea de água-CAA, capacidade de retenção de água-CRA e solubilidade da proteína-SP) e de superficie (capacidade de formação e estabilização de espumas e de emulsões) da caseína bovina obtida por coagulação enzimática. Os graus de hidrólise (GH) estudados foram: 5,7; 12,8; 20,1 e 35,8\%. Observou-se que quanto maior o GH maior a SP e menor a CRA dos hidrolisados. A hidrólise enzimática melhorou a capacidade de formação de espuma, pois o coágulo de caseína (COC) não formou espuma nas condições estudadas. A melhor capacidade de formação de espuma foi conseguida com o GH $12,8 \%$ e a maior estabilidade com GH 5,7\%. Os hidrolisados, com GH 12,8; 20,1 e 35,8\% não formaram emulsão. Não houve diferenças significativas entre o GH $5,7 \%$ e o COC quanto à formação de emulsão, mas a estabilidade da emulsão do hidrolisado de menor grau de hidrólise foi significativamente superior ao coágulo de caseína.

Palavras-chave: caseína; hidrólise enzimática; propriedades funcionais; propriedades hidrofilicas; propriedades de superficie.

\section{SUMMARY}

EFFECT OF ENZIMATIC HYDROLYSIS ON FUNCTIONAL PROPERTIES OF BOVINE CASEIN COAGULATED BY THE ACTION OF CHYMOSIN. The objective of the present work was to study the influence of degree of hydrolysis (DH) on the hydrophilic and surface functional properties of a bovine casein obtained by enzymatic coagulation (COC). The degrees of hydrolysis produced were $5.7,12.8,20.1$ and $35.8 \%$. It was observed that the higher the $\mathrm{DH}$, the higher the protein solubility and the lower the water retention capacity (WRC) of the hydrolysates. The best foaming capacity was obtained with $12.8 \% \mathrm{DH}$ and best foam stability with $5.7 \% \mathrm{DH}$. The hydrolysate with $5.7 \% \mathrm{DH}$ showed the same emulsifying capacity as the coagulated casein, however emulsion stability was superior for the $5.7 \%$ hydrolysate than for COC. The hydrolysates with higher DH $(12.8,20.1$ and $35.8 \%)$ did not form emulsion.

Keywords: casein; enzymatic hydrolysis; hydrophilic properties; surface properties.

\section{1 - INTRODUÇÃO}

A hidrólise de proteínas pode ser produzida com dois objetivos, alteração de propriedades funcionais e produção de pequenos peptídeos e aminoácidos para serem utilizados em alimentos dietéticos ou como agente flavorizante [8].

As proteinas mais utilizadas para o preparo de hidrolisados são as caseínas, as proteínas de soro do leite e a soja [10]. A caseína e seus hidrolisados enzimáticos possuem várias propriedades funcionais desejáveis e, por isso, a sua utilização em maior escala na indústria de alimentos apresenta grande interesse $[19,25]$ e estão diretamente relacionadas à solubilidade, capacidade de hidratação e retenção de água, propriedades emulsificantes e espumantes [26].

Modificações químicas e enzimáticas têm sido usadas para melhorar as propriedades funcionais das proteínas [21], no entanto a hidrólise enzimática apresenta maiores benefícios e vantagens sobre a modificação química porque inclui a especificidade da enzima em relação ao substrato, havendo pouca probabilidade de ocorrer reações indesejáveis, que resultem na formação de pro-

Recebido para publicação em 09/03/2004. Aceito para publicação em 11/08/2005 (001304).

Departamento de Alimentos e Nutrição, Faculdade de Engenharia de Alimentos, Universidade Estadual de Campinas (UNICAMP). C.P.: 6121.CEP: 13083-970, Campinas-SP.E-mail:sgarb@fea.unicamp.br A quem a correspondência deve ser enviada. dutos tóxicos, além de se processar sob condições mais brandas [18].

Os parâmetros mais importantes da reação da hidrólise são concentração de substrato (proteína), relação enzima/substrato, pH e temperatura. Além da especificidade e propriedades da enzima, existem outros parâmetros responsáveis pela trajetória da reação de hidrólise da proteína. O critério quantitativo da reação de proteólise é o grau de hidrólise [15], definido como a porcentagem de ligações peptídicas clivadas em relação ao total de ligações peptídicas [20].

Segundo PANYAM \& KILARA [17], a hidrólise enzimática da proteína resulta em: a) diminuição do peso molecular, b) aumento do número de grupos ionizáveis, c) exposição de grupos hidrofóbicos que estavam protegidos na estrutura original da proteina.

Este trabalho teve como objetivo verificar os efeitos da hidrólise controlada, pela ação da enzima comercial Flavourzyme, sobre as propriedades funcionais hidrofilicas e de superficie, da caseína coagulada enzimaticamente e de seus hidrolisados.

\section{2 - MATERIAL E MÉTODOS}

\section{1 - Material}

O material original usado para a produção de hidrolisados foi a caseína produzida através da coagulação enzimática (renina/quimosina). A coagulação foi feita a partir do leite bovino, tipo $\mathrm{B}$, desnatado e pasteurizado $\left(72^{\circ} \mathrm{C}, 20 \mathrm{seg}\right)$. O coágulo obtido (COC) pela ação da enzima renina (quimosina) foi lavado com água, homogenei- 
zado, e seco em "spray dryer" [24].

A enzima utilizada para a obtenção dos hidrolisados foi a Flavourzyme 500L (Novo Nordisk) com atividade declarada de $500 \mathrm{LAPU} / \mathrm{g}$ proteína.

O reagente utilizado para a determinação do grau de hidrólise, TNBS (2,4,6 trinitrobenzenosulfonic acid) foi de procedência Sigma P2297, 5\% p/v em solução aquosa

\section{2 - Métodos químicos}

\subsection{1 - Obtenção dos hidrolisados}

A caseína obtida por coagulação enzimática (coágulo de caseína-COC) foi hidrolisada pela ação da enzima Flavourzyme, sendo a relação enzima substrato $[\mathrm{e} / \mathrm{s}]=$ 1:9, mantendo-se temperatura constante. A reação se deu em água desionizada, suspensão de $8 \%$ de proteína $(\mathrm{p} / \mathrm{v})$ a temperatura de $38 \pm 1^{\circ} \mathrm{C}$ e em sistema descontínuo. $\mathrm{O}$ pH inicial foi o da suspensão da matéria-prima em água ( $\mathrm{pH} 7,0 \pm 0,3$ ). Durante a hidrólise não houve ajuste do $\mathrm{pH}$.

O ponto final da reação foi obtido mediante inativação térmica da enzima a $75^{\circ} \mathrm{C}$ por 10 minutos. O material obtido foi seco por liofilização.

\subsection{2 - Determinação do grau de hidrólise (GH)}

O GH foi definido segundo ADLER-NISSEN [4] como o número de ligações peptídicas clivadas ou número de grupos amino livres formados durante o processo de hidrólise, expresso em equivalente de hidrólise (h). O número total de ligações peptídicas antes da hidrólise ( $\mathrm{H}$ total) foi determinado pela composição de aminoácidos da proteína em $\mathrm{mmol} / \mathrm{g}$ de proteína.

O GH foi calculado segundo a expressão: $\mathrm{GH}(\%)=\mathrm{h}$ ( $\mathrm{n}^{\circ}$ de ligações peptídicas clivadas) / H total ( $\mathrm{n}^{\mathrm{o}}$ total de ligações peptídicas).

Para a determinação do grau de hidrólise $(\mathrm{GH})$ foi utilizado o método proposto por ADLER-NIESSEN [3]. O progresso da hidrólise foi seguido através da retirada periódica de aliquotas do meio de incubação e conseqüente inativação térmica da enzima $\left(75^{\circ} \mathrm{C}\right.$ por 10 minutos), seguido de reação com TNBS (ácido trinitrobenzeno sulfônico) para a determinação do número de ligações peptídicas clivadas.

\subsection{3 - Composição centesimal}

Teor de umidade, resíduo mineral (cinzas) e proteína $(\mathrm{N} \times 6,38)$ foram determinados de acordo com os procedimentos descritos no AOAC [1].

\section{3 - Propriedades funcionais hidrofilicas}

\subsection{1 - Capacidade de absorção espontânea de} água (CAA).

O método utilizado foi o empregado por TORGENSEN \& TOLEDO [25]. O ensaio foi conduzido à temperatura ambiente, sendo que as leituras de água absorvida foram feitas em intervalos de tempo, totalizando 30 minutos. O resultado foi expresso em $\mathrm{mL}$ de água absorvida por g de amostra.

\subsection{2 - Capacidade de retenção de água (CRA).}

Para essa determinação foi seguida a técnica de REGENSTEIN, JAUREGUI \& BAKER [23]. As dispersões tiveram os valores de $\mathrm{pH}$ ajustados para $6,5 \mathrm{com} \mathrm{NaOH}$ ou $\mathrm{HCl} 0,1 \mathrm{~N}$, e o volume aferido no final, para resultar em dispersões com $1 \%$ de proteína. A capacidade de retenção de água foi dada pela equação: $\mathrm{CRA}=$ peso amostra hidratada (g) peso amostra original (g)/ concentração de proteina (g) na amostra.

\subsection{3 - Solubilidade.}

A porcentagem de proteína solúvel (\%PS) foi determinada de acordo com o método de MORR et al. [12], que consiste em uma modificação do método de determinação do índice de nitrogênio solúvel.

Foram estudados os efeitos da força iônica produzida por cloreto de sódio $(\mathrm{NaCl})$ a diferentes concentrações (0 a $0,15 \mathrm{M}) \mathrm{em} \mathrm{pH} 6,5$ a $25^{\circ} \mathrm{C}$.

A porcentagem de proteína solúvel foi calculada como segue: $\%$ PS = concentração de proteína no sobrenadante $(\mathrm{mg} / \mathrm{mL})$ x $50 /$ peso da amostra $(\mathrm{mg})$ x conteúdo de proteína da amostra (\%).

\section{4 - Propriedades de superficie}

\subsection{1 - Formação de espuma}

A capacidade de formação de espuma foi determinada através do método descrito por MOHANTY, MULVIHILL \& FOX [11]. Foram preparadas dispersões dos hidrolisados a $3 \%$ de proteina em diferentes concentrações de cloreto de sódio $(0,00 ; 0,05$; e $0,15 \mathrm{M})$. As dispersões foram mantidas em agitação durante 30 minutos em agitador magnético. Posteriormente o $\mathrm{pH}$ das dispersões foi ajustado para 6,0 e o volume aferido para $100 \mathrm{~mL}$.

As suspensões foram batidas em batedeira Black \& Decker (cat $\mathrm{n}^{\mathrm{o}} \mathrm{M} 275,175 \mathrm{~W} 120 \mathrm{~V} 50-60 \mathrm{~Hz}$ ), na velocidade máxima (980rpm) por um periodo de 5 minutos. A espuma foi imediatamente transferida para provetas (de acordo com o volume de espuma obtido) e o volume inicial de espuma (Vo) foi registrado. A porcentagem de espuma formada (\%ESP) foi calculada: $\% \mathrm{ESP}=\mathrm{Vo}(\mathrm{mL}) /$ volume original da solução de proteína $(\mathrm{mL}) \times 100$.

\subsection{2 - Estabilidade da espuma}

A espuma foi deixada por 5 minutos em provetas de 500 ou $1000 \mathrm{~mL}$ e foram medidos, simultaneamente, o volume da coluna de espuma e o volume do líquido drenado com o decorrer do tempo. A estabilidade da espuma foi avaliada pela redução percentual do volume em relação ao seu volume inicial, conforme descrito por PATEL, STRIPP \& FRY [18]. 


\subsection{3 - Capacidade emulsificante (CE)}

A CE foi definida como a quantidade máxima de óleo que pode ser dispersa em fase aquosa para um dado procedimento experimental. Esta análise foi realizada conforme procedimento descrito por DE KANTEREWICZ et al. [5], utilizando-se o homogeneizador Ultra-Turrax T25 .

Dispersões a $1 \%$ de proteina $(\mathrm{pH} 7,0)$ e óleo foram combinados em diferentes proporções mantendo o volume total igual a $50 \mathrm{~mL}$, até encontrar o ponto onde ocorreu o colapso da emulsão, visualizada pela separação de fases e utilizando-se o corante lipossolúvel - Sudan III para facilitar essa visualização.

As emulsões foram agitadas à velocidade de 9.500rpm por um tempo de três minutos, antes de se adicionar incrementos de óleo, sendo mantidas em banho de gelo para evitar o aquecimento da amostra. A capacidade de emulsificação foi expressa em $\mathrm{mL}$ de óleo adicionado até alcançar o ponto de inversão por g de proteína.

\subsection{4 - Estabilidade de emulsão (EE)}

A EE foi determinada de acordo com a metodologia descrita por ACTON \& SAFFLE [2] com algumas adaptações às condições do laboratório. As emulsões foram feitas com $50 \mathrm{~mL}$ de óleo de soja e $50 \mathrm{~mL}$ de dispersões de proteína a $1 \%(\mathrm{pH} 7,0)$, homogeneizadas a $9.500 \mathrm{rpm}$ em homogeneizador Ultra-Turrax - T-25 por três minutos em banho de gelo.

Aliquotas de $20 \mathrm{~mL}$ foram colocadas em tubos de ensaio e deixadas por 24 horas a $37^{\circ} \mathrm{C} \pm 2^{\circ} \mathrm{C}$. Foi determinada a umidade da emulsão recém-preparada. Após 24 horas a $37^{\circ} \mathrm{C}$, removeu-se com pipeta, $5 \mathrm{~mL}$ da amostra do fundo do tubo e foi determinada a umidade. A razão estabilidade para cada amostra foi determinada com base na alteração da porcentagem de umidade (U) após 24 horas:

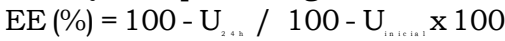

\section{5 - Análise estatística}

Todos os resultados foram analisados através da análise de variância (ANOVA) e as diferenças entre médias pelo teste de Tukey a 5\% de probabilidade [7], utilizando-se o programa "Statistica: Basic Statistics and Tables".

\section{3 - RESULTADOS E DISCUSSÃO}

\section{1 - Determinação do grau de hidrólise (GH)}

Após a obtenção dos hidrolisados determinou-se o grau de hidrólise através da reação do TNBS. Utilizou-se para o cálculo o valor $\mathrm{H}$ total $(9,88)$ a soma dos aminoácidos em $\mathrm{mmol} / \mathrm{g}$ proteína) no hidrolisado total da proteína. Nos hidrolisados enzimáticos obtidos do coágulo de caseína os graus de hidrólise determinados foram: 5,7 ; 12,$8 ; 20,1$ e $35,8 \%$.

\section{2 - Composição dos hidrolisados}

Na Tabela 1 estão mostrados os resultados obtidos para proteinas, umidade e cinzas dos hidrolisados com diferentes graus de hidrólise, comparados a do concentrado que lhes deu origem (COC). Apesar de proveniente de uma mesma matéria-prima os hidrolisados não apresentaram composição idêntica.

TABELA 1 - Composição dos hidrolisados comparados ao coágulo de caseina (COC), quanto ao teor de proteína, umidade e cinzas

\begin{tabular}{|c|c|c|c|c|c|}
\hline Componentes & $\mathrm{COC}$ & GH 5,7\% & $\begin{array}{c}G H \\
12,8 \%\end{array}$ & $\begin{array}{c}G H \\
20,1 \%\end{array}$ & GH $35,8 \%$ \\
\hline Proteina & $72,4 \pm 1,6^{\circ}$ & $69,7 \pm 0,3^{b}$ & $69,2 \pm 0,4^{b}$ & $66,5 \pm 0,7^{\circ}$ & $70,31 \pm 1,0^{b}$ \\
\hline Umidade & $4,3 \pm 0,3^{4}$ & $5,5 \pm 0,3^{e}$ & $7,6 \pm 0,6^{b}$ & $9,2 \pm 0,3^{*}$ & $8,29 \pm 0,2 a b$ \\
\hline Cinzas* & $9,3 \pm 0,1^{*}$ & $9,3 \pm 0,03 *$ & $9,3 \pm 0,1^{*}$ & $8,9 \pm 0,3 *$ & $9,51 \pm 0,02^{*}$ \\
\hline
\end{tabular}

" resultados expressos em base seca para proteina e cinzas

Resultados de 3 determinaçōes, média \pm desvio padrắo. Média seguidas por
Tukey $(\mathrm{p}>0.05)$.

Observa-se que o teor de proteína do concentrado $(\% \mathrm{~N} \times 6,38)$ foi significativamente superior a dos seus hidrolisados. Os teores de umidade foram variáveis e diferiram entre as amostras estudadas. Não houve diferenças significativas entre os teores de cinzas nos materiais estudados.

A pequena queda de proteina bruta $(\mathrm{N}$ x 6,38) detectada nos hidrolisados em relação ao material original não é de causa aparente, mas tem sido observada também em outros trabalhos [16]. Única hipótese possivel seria a perda de substâncias nitrogenadas voláteis durante aquecimento para inativação enzimática ou talvez, formação de compostos nitrogenados não detectáveis pelo método de Kjeldahl.

\section{3 - Propriedades hidrofilicas}

As propriedades hidrofilicas como capacidade de absorção de água (CAA), capacidade de retenção de água (CRA) e solubilidade da proteína (SP) foram estudadas nos quatro hidrolisados obtidos, comparativamente ao concentrado que lhes deu origem. A Figura 1 ilustra a capacidade de absorção espontânea de água (CAA) do coágulo de caseína desidratado e de seus hidrolisados.Segundo PANYAM \& KILARA [17], a hidrólise altera a conformação da proteína e produz peptídeos de cadeia curta, aumentado a disponibilidade de sítios polares, concorrendo para uma maior absorção de água.

Observa-se na Figura 1 que na amostra não hidrolisada (COC) a CAA foi significativamente superior ao hidrolisado com o maior grau de hidrólise, porém significativamente inferior ao de menor grau de hidrólise 5,7\%. Este resultado mostra que a CAA depende tanto do tamanho molécular(GH) como do balanço de grupos hidrofilicos e hidrofóbicos no material hidrolisado. Com GH médio houve um aumento significativo da CAA em virtude da diminuição do tamanho molecular ainda capaz de formar rede protéica e aprisionamento de moléculas de água, ao mesmo tempo em que ocorre maior exposição de grupos hidrofílicos. Na hidrólise excessiva (GH 35,85\%), ao mesmo tempo em que a rede protéica é desfeita há um grau de exposição de grupos hidrofóbicos. 


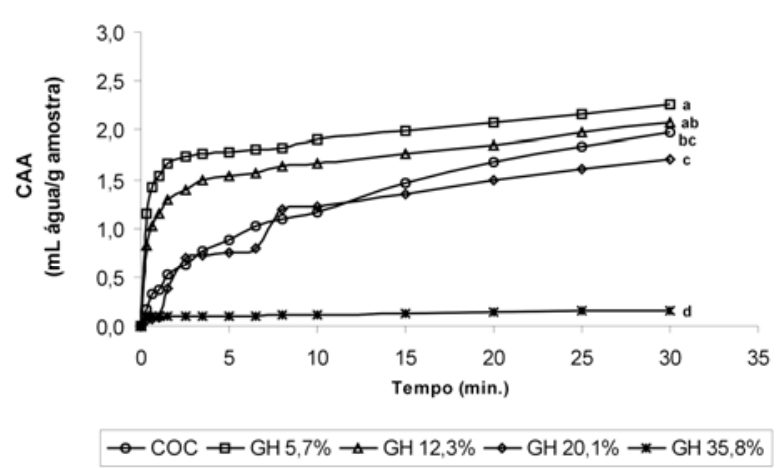

FIGURA 1 - Curvas da capacidade de absorção de água (CAA) em função do tempo para o coágulo de caseína desidratado (COC) e seus hidrolisados. Letras diferentes indicam diferenças estatísticas na CAA após $30 \mathrm{~min}$. Os pontos representam médias de três repetições

Segundo NIELSEN [14] a hidrólise extensiva das ligações peptídicas da cadeia protéica causa mudanças na estrutura das proteínas e uma maior exposição de grupos hidrofóbicos.

\section{- Capacidade de retenção de água (CRA)}

A Figura 2 ilustra a CRA dos diferentes hidrolisados obtidos a partir da caseína comparativamente ao coágulo não hidrolisado (COC).

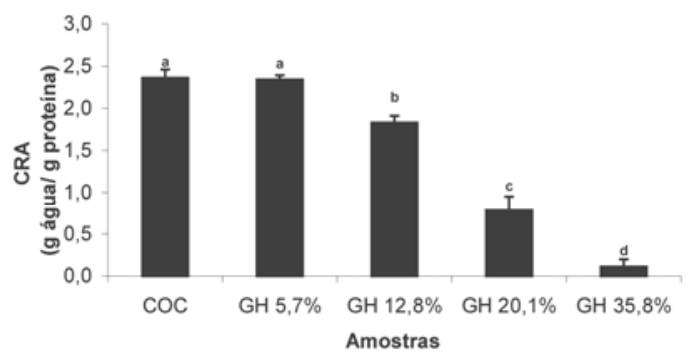

FIGURA 2 - Representação gráfica da capacidade de retenção de água (CRA) para o coágulo de caseína desidratado (COC) e seus hidrolisados. Letras diferentes indicam diferenças estatísticas na CRA em pH 6,5 (p>0,05)

Na Figura 2 observa-se que a capacidade de reter água diminuiu com o aumento do grau de hidrólise. Os hidrolisados com GH 12,8; 20,1 e 35,8\% tiveram valores de CRA significativamente inferiores quando comparados ao hidrolisado com GH 5,7\% e com o coágulo (não hidrolisado), que não diferiram entre si. Segundo KINSELLA [9], a quantidade de água associada à proteína depende de uma série de fatores, destacando-se a sua composição, conformação, número de grupos polares expostos, presença de sais, $\mathrm{pH}$, etc.

Verificou-se que os hidrolisados tiveram comporta- mentos diferentes quanto a CAA e a CRA, pois estas propriedades dependem de fatores diferentes. A CAA está relacionada principalmente com a presença de grupos hidrofilicos na superficie da proteína, enquanto que a CRA depende particularmente do tamanho molecular e da capacidade de formação de rede protéica, os hidrolisados de maior grau de hidrólise (menor peso molecular) não podem formar rede, além de apresentar maior concentração de grupos hidrofóbicos, portanto menor CRA.

Segundo PILOSOF [20], a absorção de água indica a capacidade de um material absorver a água em sua estrutura de uma forma espontânea, quando em contato com a água através de uma superficie que se mantém úmida por imersão. Por outro lado, a retenção de água indica a capacidade de um material hidratado reter água frente à ação de uma força externa de gravidade, centrifugação ou compressão dos alimentos.

\section{- $\quad$ Solubilidade protéica (\%SP)}

A Figura 3 ilustra os resultados da solubilidade em $\mathrm{pH}$ 6,5, em temperatura ambiente, nas diferentes concentrações de cloreto de sódio $(\mathrm{NaCl})$. Observa-se que quanto maior o grau de hidrólise maior a solubilidade.

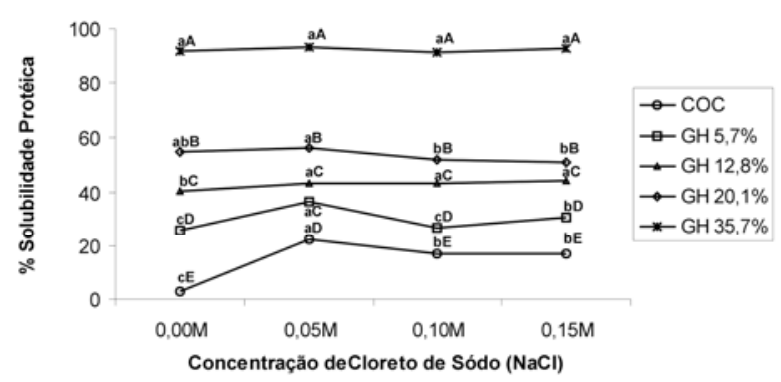

FIGURA 3 - Representação do perfil de solubilidade do coágulo de caseína (COC) e seus hidrolisados em pH 6,5 e a $25^{\circ} \mathrm{C}$. (Letras diferentes (minúsculas) indicam diferenças quanto à concentração de NACL e (maiúsculas) quanto ao GH

Segundo PANYAM \& KILARA [17], uma das principais conseqüências da hidrolise enzimática é o aumento da solubilidade e, normalmente este aumento está associado ao aumento do grau de hidrólise. O aumento da solubilidade dos hidrolisados é provavelmente devido à diminuição do tamanho das momoléculas e correspondente aumento da exposição de grupos hidrofilicos amino e carboxil ionizáveis.

A solubilidade do COC não hidrolisado e dos hidrolisados com GH 5,7 e 12,8\% em solução aquosa foi significativamente inferior à solubilidade em concentração $0,05 \mathrm{M}$ de cloreto de sódio. Nas concentrações de 0,10 e $0,15 \mathrm{M}$, o COC e os hidrolisados com GH $5,7 \%$ e $20,1 \%$ apresentaram ddiferenças significativas de solubilidade, inferior a $0,15 \mathrm{M}$. A maior solubilidade foi conseguida com o GH 35,8\%, não havendo influência significativa quanto às concentrações salinas estudadas. Com rela- 
ção aos diferentes GH analisados na mesma concentração de cloreto de sódio, observou-se que o grau de hidrólise altera de forma significativa as propriedades interfásicas dos hidrolisados.

\section{4 - Propriedades de superficie}

\section{- Propriedades espumantes}

A Figura 4 mostra o efeito do GH sobre a capacidade de formação de espuma dos hidrolisados do coágulo de caseína. O coágulo original não formou espuma, bem como o hidrolisado de maior GH (35,8\%).

Observa-se que a maior expansão de espuma foi conseguida com o hidrolisado com $12,8 \%$ de grau de hidrólise em água e $0,05 \mathrm{M}$ de $\mathrm{NaCl}$, igualando-se a $0,15 \mathrm{M}$ de $\mathrm{NaCl}$ e 20,1\% GH. A concentração salina são influenciou a expansão de espuma no hidrolisado com $5,7 \% \mathrm{GH}$.

Não somente fatores relacionados com o GH podem influir no desempenho das propriedades de espuma, mas também o $\mathrm{pH}$ e outros aspectos relacionados à composição dos hidrolisados em questão [6]. A massa molecular é importante, pois peptídeos de elevada massa molecular influem sobre as características espumantes dos peptídeos de baixo peso molecular [13], desestabilizando a espuma [14].

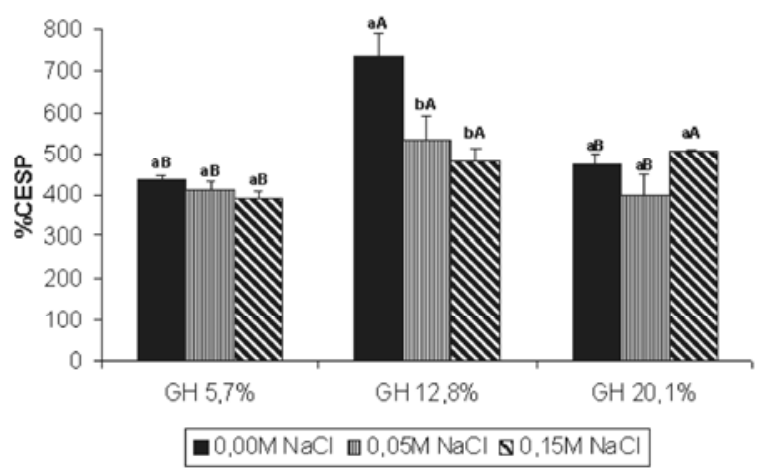

FIGURA 4 - Gráfico da capacidade de expansão de espuma (\%ESP) para os três hidrolisados de coágulo de caseína em $\mathrm{pH}$ 6,0 e em função de diferentes concentrações de cloreto de sódio. Letras iguais (minúsculas) indicam que não houve diferença estatística a $5 \%$ de probabilidade para o mesmo GH em função da concentração salina. Letras minúsculas se referem à mesma concentração salina para diferentes GH

A formação e a estabilidade de espumas em sistemas protéicos é dependente de uma série de fatores que, no presente trabalho, não foram avaliados. Segundo KINSELA [9], o ideal para que uma proteina apresente o melhor desempenho na formação e estabilidade de espuma, é que possua em peso molecular maior que 20Kda, um mínimo de carga liquida, presença de sítios de ligações hidrofóbicas, além de uma conformação flexível. Segundo as conclusões de FURTADO et al. [6] não somente fatores relacionados ao grau de hidrólise podem in- fluir no desempenho das propriedades de espuma, mas também o $\mathrm{pH}$ e outros aspectos relacionados à composição dos hidrolisados.

A cinética de desestabilização da espuma em pH 6,0 em função do tempo está representada nas Figuras 5, 6 e 7 , respectivamente, para os hidrolisados com 5,$7 ; 12,8 \mathrm{e}$ $20,1 \%$ de grau de hidrólise.

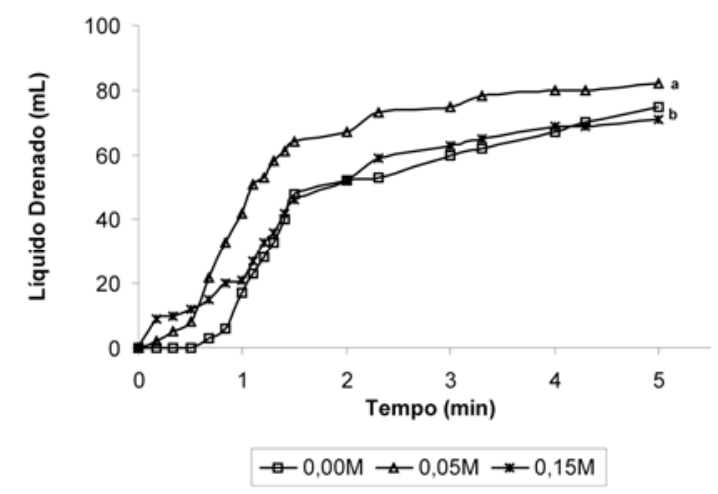

FIGURA 5 - Representação gráfica da estabilidade da espuma do hidrolisado com GH 5,7\% em função da concentração de $\mathrm{NaCl}$ em $\mathrm{pH}$ 6,0. Letras diferentes indicam diferenças estatísticas do líquido drenado após $5 \mathrm{~min}$ (300seg)

Na Figura 5 pode-se observar que a estabilidade da espuma foi maior em solução aquosa e em solução de $0,15 \mathrm{M} \mathrm{NaCl}$, as quais não diferiram estatisticamente. $\mathrm{Na}$ concentração de $0,05 \mathrm{M}$ de cloreto de sódio a estabilidade foi menor, pois a perda de líquido, nesta concentração salina é significativamente superior a da espuma estabilizada em água e em solução de $0,15 \mathrm{M}$ de $\mathrm{NaCl}$.

Observa-se que em 60 seg a estabilidade da espuma do hidrolisado com 5,78\% de menor grau de hidrólise (Figura 5) foi bem superior (menor volume drenado) que os hidrolisados com 12,8 e $20,1 \%$ de grau de hidrolise, Figuras 6 e 7, respectivamente.

A estabilidade da espuma diminui e a capacidade de formação de espuma aumenta com o aumento do grau de hidrólise. Isso sugere que as propriedades moleculares afetam a capacidade de formação e a estabilidade de espuma dos hidrolisados de forma diferente [14].

Verificou-se nos hidrolisados com menor estabilidade (GH 12,8 e 20,1\%) que não houve diferenças significativas entre as concentrações salinas estudadas, sendo que o hidrolisado com $12,8 \%$ de grau de hidrólise foi mais estável que o de $20,1 \%$ confirmando que, quanto maior o grau de hidrólise menor a estabilidade da espuma. TURGEON, GAUTHIER \& PAQUIN [26] relataram que, apesar de pequenos peptídeos se difundirem rapidamente na interface e serem adsorvidos, eles serão menos eficientes na redução da tensão superficial, por dificuldade de se reorientarem na interface água-ar e formarem membrana continua visco-elástica. 


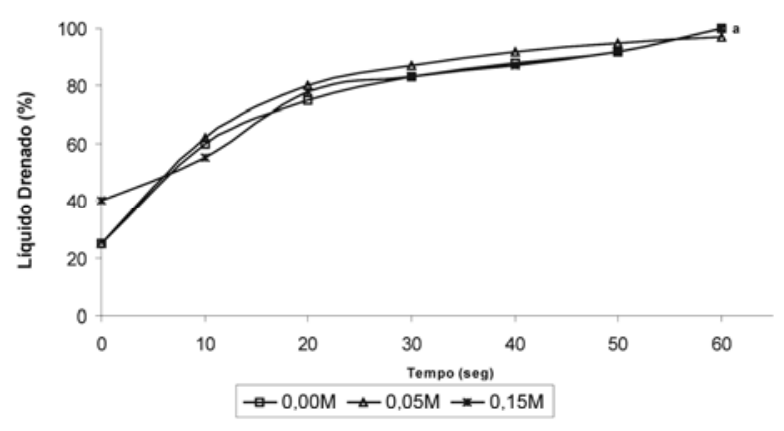

FIGURA 6 - Representação gráfica da estabilidade da espuma do hidrolisado com GH 12,8\% em água e em função da concentração de $\mathrm{NaCl}$ em $\mathrm{pH}$ 6,0

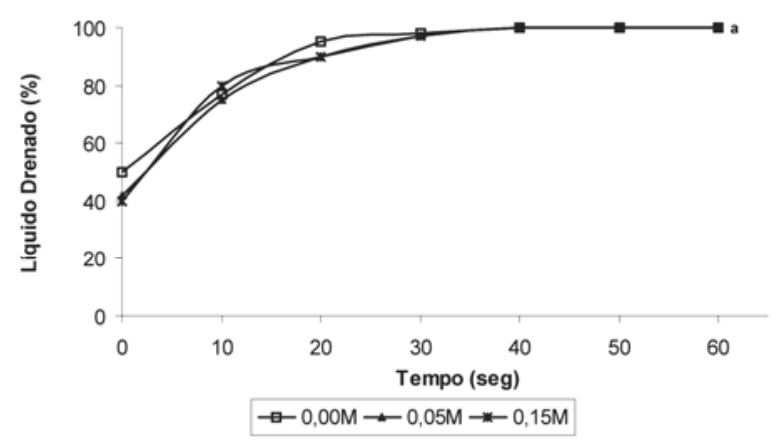

FIGURA 7 - Representação gráfica da estabilidade da espuma do hidrolisado com GH 20,1\%, em água e em função da concentração de $\mathrm{NaCl}$ em pH 6,0

- Propriedades emulsificantes

A hidrólise parcial das proteínas geralmente aumenta o número de grupos polares e hidrofilicos, diminui o peso molecular, altera a estrutura globular das proteínas podendo expor maior número de grupos hidrofóbicos. Estas alalterações podem afetar as propriedades emulsificantes [14].

De acordo com PANYAM \& KILARA [17], peptídeos maiores promovem maior estabilidade da emulsão, ao passo que a presença de peptídeos menores prejudica a estabilidade. A hidrólise extensiva das proteínas resulta em uma drástica perda das propriedades emulsificantes e a atividade emulsificante da caseina diminui linearmente com o grau de hidrólise.

Dos hidrolisados produzidos, somente o de menor grau de hidrólise possui propriedades emulsificantes, pois as "emulsões" dos demais hidrolisados eram desestabilizadas antes mesmo da homogeneização do material (batimento de $3 \mathrm{~min}$ ).

Segundo FURTADO et al. [6], pouca ou nenhuma estabilidade das emulsões da grande maioria dos hidrolisa- dos desidratados foi observada, independente de sua origem ou do $\mathrm{pH}$ em que foi analisada.

A Tabela 2 ilustra os resultados obtidos para a capacidade de formação e de estabilidade da emulsão do hidrolisado com 5,7\% de grau de hidrólise comparado ao do concentrado que lhe deu origem (coágulo de caseína).

TABELA 2 - Resultados obtidos para capacidade emulsificante (CE) e estabilidade da emulsão (EE) para o coágulo de caseîna (COC) e o hidrolisado com GH 5,7\%

\begin{tabular}{lcc}
\hline Amostras & $C E$ & $E E$ \\
& $(m L$ de óleo/g proteína) & $(\%)$ \\
\hline COC & $129,2 \pm 3,2^{\mathbf{a}}$ & $55,5 \pm 1,3^{\mathbf{b}}$ \\
GH $5,7 \%$ & $134,9 \pm 5,8^{\mathbf{a}}$ & $83,6 \pm 2,0^{\mathbf{a}}$ \\
\hline a,b Resultados de 3 determinaçóes, média \pm desvio padråo. Média seguidas por \\
$\begin{array}{l}\text { uma mesma letra minúscula (coluna) nấo diferem entre si pelo teste de Tukey } \\
\text { (p }>0,05) .\end{array}$
\end{tabular}

As propriedades emulsificantes das proteinas também dependem da solubilidade inicial. Quanto mais dissolvida a proteina estiver no sistema da emulsão, mais efetiva poderá ser a interface entre a fase óleo e a fase contínua durante a emulsificação [22]. No entanto, a formação de um filme interfacial coesivo e elástico por adsorção de moléculas de proteína na interface, poderá ser dificultada pela predominância de pequenos peptídeos. Esta pode ser uma razão da diminuição da estabilidade [9] e a não formação de emulsão dos hidrolisados com elevados graus de hidrólise.

\section{4 - CONCLUSÕES}

Verificou-se no presente estudo que as propriedades funcionais da caseína coagulada enzimaticamente são diferentes das de seus hidrolisados. O grau de hidrólise influenciou marcadamente as propriedades hidrofilicas e de superficie da caseína obtida por coagulação enzimática.

A maior capacidade de absorção de água foi do hidrolisado com 5,7 e 12,8\% de grau de hidrólise, que não mostraram diferenças significativas entre si. Hidrólises mais extensivas tiveram valores de absorção de água inferiores aos do coágulo de caseína.

A solubilidade aumentou proporcionalmente ao $\mathrm{GH}$. O hidrolisado com $5,7 \%$ de grau de hidrólise apresentou a maior CRA que não diferiu estatisticamente do COC, sendo estes significativamente superiores aos demais hidrolisados.

A maior expansão de espuma foi conseguida com grau de hidrólise de $12,8 \%$ e a maior estabilidade de espuma foi observada no hidrolisado com GH 5,7\%. O hidrolisado de maior grau de hidrólise, GH 35,8\%, não apresentou propriedades funcionais de superficie, nas condições estudadas.

Propriedades emulsificantes foram verificadas apenas no hidrolisado com $5,7 \% \mathrm{GH}$, que não diferiu do COC quanto à capacidade emulsificante tendo porém formado emulsão significativamente mais estável que o coágulo. 


\section{5 - REFERÊNCIAS BIBLIOGRÁFICAS}

[1] A.O.A.C. Association of Official Analytical Chemists Official Methods of Analysis, W. Horwtz (ed.), $15^{\text {t" }}$ edition, Washington, D.C., 1990.

[2] ACTON, J.C.; SAFFLE, R.L. Stability of oil-in-water emulsions. 1- Effect of surface tension, level of oil, viscosity and type of meat protein. Journal of Food Science. Chicago, v.35, n.1, p.852-855, 1970.

[3] ADLER-NISSEN, J. Determination of the degree of hydrolysis of food protein hydrolysates by trinitrobenzenesulfonic acid. Journal of Agriculture and Food Chemistry. Washington, v.27, n.6, p.12561262, 1979.

[4] ADLER-NISSEN, J. Enzymic hydrolysis of food proteins. London: Elsevier Applied Science, 426 p., 1986.

[5] DE KANTEREWICZ, R.J.; ELIZALDE, B.E.; PILOSOF, A.M.R.; BARTHOLOMAI, G.B. Water-oil absorption index (WOAI): a simple method for predicting the emulsifying capacity of food proteins. Journal of Food Science, Chicago, v.52, n.5, p.1381-1383, 1987.

[6] FURTADO, M.A.M.; GOMES, J.C.; SILVA, C.A.S.; ORNELLAS, C.B.; SILVESTRE, M.P.C. Propriedades funcionais de hidrolisados de proteína lá ctea co-precipitada. Ciência Agrotécnica. Lavras, v.25, n.3., p.625-639, 2001.

[7] GOMES, F.P. Curso de estatística experimental. 10 ed., São Paulo: Nobel, 430p., 1982.

[8] KILARA, A. Enzyme-modified protein foods ingredients. Process Biochemistry. Wattford, v.20, n.5, p.149-157, 1985.

[9] KINSELLA, J.E. Milk proteins: physicochemical and functional properties Critical Review in Food Science and Nutrition. v. 21, p. 197-262, 1984.

[10] LAHL, W. J.; BRAUN, S. D. Enzymatic production of protein hydrolysates for food use. Food Technology. Chicago, v.48, n.10, p. 68-71, 1994.

[11] MOHANTY, B. MULVIHILL, D.M.; FOX, P.F. Emulsifying and foaming properties of acidic caseins and sodium caseinate. Food Chemistry. Barking, v.28, n.1, p.17-30, 1988.

[12] MORR, C. V.; GERMAN, B.; KINSELLA, J.E.; REGENSTEIN, J.P.; BUREN, V.; KILARA, A.; LEWIS, B.A.; MANGINO, M.E. Collaborative study to develop a standardized food protein solubility procedure. Journal of Food Science. Chicago, v.50, n.6, p. 1715-1718, 1985.

[13] MUTILANGI, W.A.M., PANYAM, D.; KILARA, A. Functional properties of hydrolysates from proteolysis of heat-denatured whey protein isolate. Journal of Food Science. v.61, n.2, p. 270-303, 1996.

[14] NIELSEN, P.M. Functionality of protein hydrolyses. In: Food proteins and their applications. Srinivasan Damodaram and Alain Paraf (eds). New York: Macel Dekker, INC, Cap. 15, p. 443-472, 1997.
[15] NIELSEN, P.M.; OLSEN, H.S. Enzymic modification of food protein. In: "Enzymes in food technology" . Robert J. Whitehurst and Barry A. Law (eds.) Sheffield Academic Press, Cap. 6, 109-143, 2002.

[16] PACHECO, M.T.B.; AMAYA FARFAN, J.; SGARBIERI, V.C. Partial characterization of a whey protein and its enzymes hydrolysates. Journal of Food Biochemistry. 26: 327-338, 2002.

[17] PANYAM, D., KILARA, A. Enchanting the functionality of food proteins by enzymatic modification. Trends in Food Science \& Technology. Cambridge, v.7, n.4, p.120-125, 1996.

[18] PATEL, P.D.; STRIPP, A.M.; FRY, J.C. Whipping test for the determination of foaming capacity of protein: a collaborative study. International Journal of Food Science and Technology. London, v.23, n.1, p57-63, 1988.

[19] PHILLIPS, R.D.; BEUCHAT, L.R. protein functionality in foods. ACS Symposium Series, Washington D.C., p. 275, 1981.

[20] PILOSOF, A.M.R. Propriedades de Hidratacion.. In: "Caracterizacion funcional y estructural de proteinas". Ed. Pilosof, A.M.R \& Bartholomai G. B. Buenos Aires: Aeudeba, 2000. Cap.1, p.17-28, 2000.

[21] POMERANZ, Y. Functional properties of food components. $2^{\circ}$ ed. San Diego: Academic Press, Inc., 569 p., 1991

[22] QI, M.; HETTIARACHCHY, N.S.; KALAPATHY, U. Solubility and emulsifying properties of soy proteins isolates modified by pancreatin. Journal of Food Science.v.62, n.6, p.1110-1115, 1997.

[23] REGENSTEIN, J.M.; JAUREGUI, C.A.; BAKER, R. The effect of $\mathrm{pH}$, phyphosphates and different salts on water retention properties of ground trout muscles. Journal of Food Biochemistry. Trumbull, v.8, n.2, p.123-131, 1984.

[24] ROMAN, J.A.; SGARBIERI, V.C. Obtenção e caracterização química e nutricional de diferentes concentrados de caseína. Revista de Nutrição, Fev 2005, v.18, n.1, p.75-83, 2005.

[25] TORGENSEN, H.; TOLEDO, R.T. Physical properties of protein preparation related to their functional characteristics in comminuted meat systems. Journal of Food Science. Chicago, v. 42, n.6, p.1615-1620 e 1645, 1977.

[26] TURGEON, S.L.; GAUTHIER, S.F.; PAQUin, P. Emulsifying property of whey peptide fractions as a function of $\mathrm{pH}$ and ionic strength. Journal of Food Science. Chicago, v.57, n.3, p.601-604, 1992.

\section{6 - AGRADECIMENTOS}

Os autores agradecem à FAPESP (Fundação de Amparo à Pesquisa do Estado de São Paulo) pelo apoio financeiro e pela concessão de bolsa à autora J.A.R. 